\title{
The problem of motivational support in teaching the Ukrainian language
}

\author{
Sergey Yekimov ${ }^{1}$, Ganna Getmanets ${ }^{2}$, Larysa Miroshnik², Victoriia Tsypko ${ }^{3}$, and Oksana \\ Danylovych $^{4}$ \\ ${ }^{1}$ Publishing House "Education and Science” s.r.Oб Olstynska 607/1, Praha 8, 18100 ,Czech \\ Republic \\ 2Kharkiv National Medical University, Kharkiv, Ukraine \\ ${ }^{3}$ National Transport University, Kiev, Ukraine \\ ${ }^{4}$ Yuriy Fedkovych Chernivtsi National University, Chernivtsi, Ukraine
}

\begin{abstract}
Within the framework of this study, the problem of motivational support in learning the Ukrainian language was studied. It shows the importance and necessity of motivating students to increase their interest in learning and acquiring new knowledge. Creating a creative work environment in the classroom allows students to feel more talented and intelligent. A great role in stimulating language learning can be played by the study of folk folklore.
\end{abstract}

\section{Introduction}

According To O'Farrell, Suzanne. (2018), Coldwell, David. (2016) there are two main approaches regarding motivational support in the educational process. The first of them is to search for individual means to form motivation based on its properties. In the second approach, the content of motives forms the effectiveness of activities.

According to AL-KAISI, Alisa \& Arkhangelskaya, Alla \& Rudenko-Morgun, Olga \& Lopanova, Elena. (2019) it is necessary to study the essence of the educational process in order to achieve greater effectiveness of motivational support in training. Students' activities are based on a specific situation. In this connection, the teacher must first of all achieve involuntary attention in students, and only after that strive to achieve voluntary attention in them. In order for a student to take an active position in the educational process, he must first of all understand the meaning and necessity of the material being studied.

According To Berns, Margie. (2007), Sardegna, Veronica. (2020) the teacher must first inform students about the material being studied and convince them of the need for new knowledge to be acquired for their future profession or practice. Actualization of the need for study should occur through the disclosure of aesthetic, Gnostic and social significance. At the second stage, the student determines the motivation for educational activities based on the needs formed at the previous stage. At the third stage, the student determines the goals, which determines his actions during the study of educational material.

According to Wirentake, Wirentake. (2017) the active essence of a person is determined by its motives. They are reflected in behavior, character, psychological processes, abilities, 
and emotions. The motive takes into account all the interests of the individual in accordance with the external factors affecting it.

According to Ravasco Nobre, Carla. (2018) motive is defined as the conscious activity of an individual to satisfy their needs. The motive of human activity is directly related to its needs and this relationship passes through intentions and decision-making. Human activity usually corresponds to several motives at the same time. Some motives are stimulating, while others are meaning-forming. Sense-forming motives usually prevail over stimulating motives.

According to Chumarova, Lyubov \& Gataullina, Rosa \& Fassakhova, Guzel \& Islamova, Liliya. (2016), the motif is an attitude to the surrounding world based on the phenomenology of the individual's psyche. The significance of the motive in human activity involves not only participation in the activity, but also goes beyond it. We can distinguish the so-called potential ones, they are not related to a specific person's activity, but they have a General impact on their motivational orientation .

According to Bender, Bernd. (2002) features of a person's character contains a set of human motives formed throughout his life.

The repeated appearance of motivational education in the mind of an individual and its implementation in their actions and behavior leads to the fact that this motivational education becomes a character trait of this individual, his personal qualities. Situational motivation is closely correlated with the content of the motive that is formed during the preparation and implementation of related activities.

According To Malouff, \& M, John \& Rooke, S \& Nicola, Serroni \& Foster, Roxanne \& Bhullar, Navjot \& Navjot,. (2008), Padhi, Lili \& Mishra, Deepanjali \& Chatterjee, Papiya \& Ojha, Jyotirmayee \& Sain, Mangal. (2019) to ensure the regulation of human activity, it is necessary to focus on the images of certain elements of the surrounding world, and they will be the guidelines that regulate activity.

This role is played by situational meanings, these meanings play a crucial role in the development of motivation

For a school student, self - determination of goals is a rather difficult task. In this regard, we believe that before starting a class, the teacher should first tell the students what he wants to teach them, where this knowledge can be useful and how the new knowledge will be evaluated. This approach, first of all, focuses the attention of students, motivates them to learn new knowledge, and increases their interest in the learning process . Getting preliminary information allows the student to more clearly understand how to perform the task and in the process of its implementation to understand why it is necessary and how to do it.

According to Felten, Peter \& Finley, Ashley. (2013) you can motivate students during the lesson:

1) Focusing their attention on the material being studied;

2) Clearly set the learning goal;

3) Encouraging students to complete learning tasks;

4) Providing students with confidence for their actions

in the process of completing tasks; 
According to Lamb, Martin. (2020), Padi, Lili \& Mishra, Deepanjali \& Chatterjee, Papaya \& Ojha, Jyotirmayee \& Sain, Mangal. (2019) strengthening students ' motivation it is necessary to focus on the implementation of the education of the student as a person. The teacher, by stimulating a sequence of motivational States, proceeds to influence the whole personality.

In accordance with the Nawab, Ali. (2012), P, Malathy. (2019) it is proposed to use project-based learning tools to increase students ' motivation to complete the educational process.

Learning through the project method involves a creative approach, as a result of which students gain new skills and knowledge during the implementation of projects, which in turn increases their attraction to certain problems, gives them the opportunity to Express themselves and self-actualization, and as a result, increases the motivation to acquire new knowledge and skills.

\section{Methods}

Within the framework of this work, an analytical research method was used, through which the studied problems were considered in unity and development. Taking into account the tasks and goals of this research, the functional-structural method of scientific research was applied.

This, in turn, provided an opportunity to study a number of aspects of the problem of motivational support in teaching the Ukrainian language.

\section{Results}

In Ukraine, the only state language is Ukrainian, and most school subjects in Ukrainian schools are taught in Ukrainian. In the Eastern regions of Ukraine, Russian is still widely spoken. And often there is a problem that due to poor knowledge of the Ukrainian language, students do not do well in other subjects in which they are taught. Therefore, in this work, we studied the problems of motivational support in teaching the Ukrainian language.

As the object of training, we chose students of the 4th grade of secondary school No. 5 in Kharkiv.

At the beginning of the study, we asked students to write a test dictation in the Ukrainian language. Based on its results, we made a conclusion that about $30 \%$ of students had problems with spelling.

A survey of students showed that they are not interested in the Ukrainian language lessons, they learn the spelling rules, but only for the reason that they do not get a bad grade in the lesson. From which we concluded that the motivation for learning the Ukrainian language lessons is low. It turned out that some students learned Ukrainian with satisfaction, while others did not, they were bored in the classroom ,they did not have a need for knowledge and did not have interest in learning.

To solve this problem, we have developed and implemented a set of measures to increase the motivation of students in Ukrainian language lessons.

According to our recommendations, in order to increase motivation in learning, it was proposed to create conditions in the classroom in which students will have additional incentives to learn (various cases were solved, children solved Ukrainian-language crosswords, played mini-performances in Ukrainian). The role of the teacher was to monitor the motivation of students and stimulate development with the help of certain pedagogical tools. 
This made it possible to include each student in creative activities, which in turn stimulated the development of their needs in learning the Ukrainian language.

Joint creative activities gave students the opportunity to show their individuality, feel smart and talented.

Ordinary lessons have been transformed into creative lessons, they have become more interesting and diverse.

After the study, we conducted an additional dictation for students of the class on the basis of which we conducted research .

The result showed that the spelling literacy of students increased by about $10-15 \%$ compared to the beginning of the study.

\section{Discussion}

A modern Ukrainian school should prepare graduates for active work in various fields of activity. In our opinion, students ' creativity plays an important role in the development of motivation. The formation of a positive attitude to the learning process among schoolchildren causes them to crave knowledge. The level and quality of students' knowledge depends on their attitude to teachers. In our opinion it helps to increase motivation to study:

1) application of new teaching methods;

2) demonstration of the practical value of the acquired knowledge;

3) novelty of the studied material;

4) teamwork of students in the classroom;

5) friendly attitude of the teacher to the students;

6) use of interactive forms of learning;

7) creating a creative microclimate in the classroom;

8) objective assessment of students' knowledge;

9) setting a clear goal for students to achieve in the classroom;

10) mastering the techniques of independent mental activity.

To increase motivation in learning the Ukrainian language, in our opinion, it is necessary to instill in students an interest in Ukrainian literature, culture, folk art and the history of the Ukrainian people.

The teacher's speech during the lesson, in our opinion, also pays great attention to the motivation of students. They have positive emotions when the teacher expresses respect for each student, awakens a sense of justice and humanism. To do this, the teacher must,

In our opinion, first of all, at the beginning of the lesson, to encourage students ' interest in the lesson and maintain it throughout the lesson, while it is important to take into account the level of development of students and other characteristics of the audience. In addition to the class-based form of classes, in our opinion, to increase motivation, you can use the following types of extracurricular activities: work groups, consultations , homework, independent reading, elective classes.

\section{Conclusions}


Children's motivation to learn may be negative . It is associated with possible bad marks, punishment by parents, reproaches from others, or positive . Positive motivation is associated with academic success, gaining new knowledge and skills, and good feedback from others.

Such motivational factors as the availability of skills, the need for sensory and emotional assessment of activities contributes to the growth of motivation to learn. The presence of a motive is, in our opinion, the main condition for a successful learning process and means its proper organization. Conversely, learning without motivation means that there are shortcomings in its organization

\section{References}

1. Alisa AL-KAİSİ, Alla Arkhangelskaya, Olga Rudenko-Morgun, Elena. Lopanova, International E-Journal of Advances in Education, 5, 275 (2019)

2. Bernd Bender, Conceptions for Purposive and Motivating Teaching (2002)

3. Margie Berns, World Englishes, 6, 79(2007)

4. Lyubov Chumarova, Rosa Gataullina, Guzel Fassakhova, Liliya Islamova, FOLKLORE IN TEACHING LANGUAGES (2016)

5. David Coldwell, Teaching language (2016)

6. Peter Felten, Ashley Finley, Cases on Quality Teaching Practices in Higher Education. 228 (2013)

7. Martin Lamb, Motivational Teaching Strategies (2020)

8. M, Malouff, R. John, S. Nicola, Foster Serroni, Bhullar Roxanne, Navjot Navjot, Methods of motivational teaching. ERIC Online Document, 499496 (2008)

9. Ali.Nawab, Academic Research International, 2, 696 (2012)

10. Suzanne O'Farrell,. Teaching languages. SecEd, 6 (2018)

11. Lili Padhi, Deepanjali Mishra, Papiya Chatterjee, Jyotirmayee Ojha, Mangal Sain,. Strategies of Learning: A Methodology of Teaching Language Through Digitalisation, 697 (2019)

12. P. Malathy, Kongunadu Research Journal, 1, 4 (2019)

13. Carla Ravasco Nobre, TEACHING LANGUAGES TO CHILDREN, 7835 (2018)

14. Veronica Sardegna, Motivational teaching strategies for pronunciation (2020)

15. Wirentake Wirentake, Jurnal TAMBORA, 2 (2017). 